Archived version from NCDOCKS Institutional Repository http://libres.uncg.edu/ir/asu/

\title{
Appalachïan
}

B O O N E, NORT H C A R O L I A

\section{Alternative Marketplaces In The 21 st Century: Building Community Through Sharing Events}

\author{
By: Pia A. Albinsson and B. Yasanthi Perera
}

\begin{abstract}
We examine alternative consumption including collaborative consumption, sharing, and unconsumption (i.e., postconsumption activities such as upcycling, reuse, recycling, etc.) at non-monetary-based private and public sharing events including Really Really Free Markets (RRFMs). These alternative marketplaces (RRFMs) were initially organized by the Anarchist Movement as a form of resistance to the capitalist economic model. However, many consumer groups now utilize this model to stage public sharing events as a means of raising awareness about various issues including sustainability and overconsumption. Participants bring, share, and take goods without any expectation of monetary or other exchange. There is limited research on collaborative consumption and sharing in non-monetary marketplaces. We address this gap by exploring alternative marketplaces, organized by consumers for consumers, utilizing qualitative research methods. Our findings indicate that a sense of community is both a driver of participation and an outcome of these events. Organizers and participants utilize these venues to share knowledge and possessions for various ideological and practical reasons. Our findings also indicate that these events challenge the entrenched notions of exchange and reciprocity. Our research contributes to the literature by highlighting the importance of community, collaboration, and changing consumer mindsets to the success of such sharing efforts.
\end{abstract}

Albinsson, P. and Perera, B. (2012), Alternative marketplaces in the 21 st century: building community through sharing events. Journal of Consumer Behaviour : An International Research Review. Wiley, ISSN 1472-0817, ZDB-ID 2194377-1. - Vol. 11.2012, 4, p. 303-315. DOI: 10.1002/cb.1389. Publisher version of record available at: https://onlinelibrary.wiley.com/journal/14791838 


\title{
Alternative marketplaces in the 21st century: Building community through sharing events
}

\author{
PIA A. ALBINSSON ${ }^{1 *}$ and B. YASANTHI PERERA ${ }^{2}$ \\ ${ }^{1}$ Appalachian State University, The Walker College of Business, Department of Marketing, Boone, NC, USA \\ ${ }^{2}$ New Mexico State University, College of Business, Department of Management, Las Cruces, NM, USA
}

\begin{abstract}
We examine alternative consumption including collaborative consumption, sharing, and unconsumption (i.e., postconsumption activities such as upcycling, reuse, recycling, etc.) at non-monetary-based private and public sharing events including Really Really Free Markets (RRFMs). These alternative marketplaces (RRFMs) were initially organized by the Anarchist Movement as a form of resistance to the capitalist economic model. However, many consumer groups now utilize this model to stage public sharing events as a means of raising awareness about various issues including sustainability and overconsumption. Participants bring, share, and take goods without any expectation of monetary or other exchange. There is limited research on collaborative consumption and sharing in non-monetary marketplaces. We address this gap by exploring alternative marketplaces, organized by consumers for consumers, utilizing qualitative research methods. Our findings indicate that a sense of community is both a driver of participation and an outcome of these events. Organizers and participants utilize these venues to share knowledge and possessions for various ideological and practical reasons. Our findings also indicate that these events challenge the entrenched notions of exchange and reciprocity. Our research contributes to the literature by highlighting the importance of community, collaboration, and changing consumer mindsets to the success of such sharing efforts.
\end{abstract}

\section{INTRODUCTION}

Sustainability is a ubiquitous topic in the 21 st century marketplace. Corporations publicize their sustainability efforts, and consumer groups seek sustainable solutions against the backdrop of the impending energy crises, ongoing environmental degradation, and the global financial meltdown. The need for sustainability is exacerbated by increasing levels of global consumption and the associated increase in demand for goods and services in international markets. Within this broad context, scholars, consumers, and the media are increasingly highlighting alternate, more responsible forms of consumption and disposition practices. This may be in part due to increased awareness of the negative societal and personal consequences of overconsuming material goods, as well as the global financial downturn of the late noughties (i.e., the first decade of the 21 st century). An increase in collaborative consumption, which contrasts with the individualistic-oriented North American and Western European consumer culture, indicates that consumer preferences, albeit yet for a relatively small segment of the entire population, are undergoing a transformation. Sheth et al. (2011) referenced a "new normal" with respect to consumers' mindset. They wrote, "American consumers in increasing numbers are turning to frugality, and a majority of them are unlikely to turn back to over-consumption" (p. 30). Indicative of this shift, consumer groups have started to resist hyperconsumption (Albinsson et al., 2010), adopt anticonsumption practices (Black and Cherrier, 2010), and explore options for simplifying, or downshifting, their lifestyles (Etzioni, 2009).

*Correspondence to: Pia A. Albinsson, Appalachian State University, The Walker College of Business, Department of Marketing, Raley Hall 4113, Boone, NC 28608, USA.

E-mail: albinssonpa@appstate.edu
In certain instances, entire communities are pioneering initiatives addressing various facets of responsible, sustainable, consumption. For instance, certain communities foster local-level development through creating "local money" to encourage localization of the economy (North, 2010). Others, even entire towns and cities, are incorporating transition initiatives that address climate change and peak oil challenges to foster ecological resilience and develop a sustainable future (Hopkins, 2008). Although these efforts yet occur on a small scale, they represent ways in which knowledgeable consumers are countering the traditional consumption-oriented paradigm by integrating the sustainability ethos into their communities.

Within this context, sharing and swapping, both forms of collaborative consumption (Botsman and Rogers, 2010), have garnered much interest as diverse groups (friends, neighbors, universities, civic groups, and online communities) organize sharing events in various forms through numerous venues. Economist Juliet Schor (2011), in writing about an alternative plentitude economy, referred to the increase in sharing, bartering, and other exchanges in society as a "wave of social innovation" fueled by the sustainability movement, facilitated by the Internet, and brought into the mainstream by the economic downturn. Recent consumer research on collaborative consumption (i.e., how consumers rent, lend, and share goods and services) has examined online and offline barter and auction sites (e.g., Freecycle. org, eBay) (Nelson et al., 2007; Cheetham, 2009; Nelson and Rademacher, 2009; Arsel, 2010); toy libraries (Ozanne and Ballantine, 2010); flea markets, swap meets, and clothing exchanges (Belk et al., 1988; Sherry, 1990; Albinsson and Perera, 2009; Denegri-Knott and Molesworth, 2009); and car sharing programs (Jonsson, 2007; Bardhi and Eckhardt, 2010). The consumer behaviors reported in these 
studies are sometimes related to marketplace resistance (Penaloza and Price, 1993; Cherrier, 2009; Albinsson et al., 2010; Izberk-Bilgin, 2010), downshifting, and voluntary simplicity (Schor, 2001; Etzioni, 2009; Shaw and Moraes, 2009; Ballantine and Creery, 2010; Black and Cherrier, 2010).

These alternative forms of consumption may connote "anticonsumption," a form of resistance that is "both an activity and an attitude" Cherrier (2009: p. 181). Although anticonsumption literally means "against consumption" (Lee et al., 2009), it is reasonable to posit that consumers who identify as such understand this term to mean antioverconsumption or anticonsumption of goods that are detrimental to personal and societal well-being, as some level of consumption is necessary to maintain life in modern societies. Thus, alternative, or conscientious consumption may be forms in which consumers choose to enact their anticonsumption sentiments. Anticonsumption practices manifest in different forms from the deliberate consumption of one brand over another to resistance or rejection of consumption in general (Zavestoski, 2002). Consumers' motivations stem from a wide range of ideals including culture, socialization (Albinsson et al., 2010), negative market-based experiences, and political ideology (Sandikci and Ekici, 2009). At the core, consumers' anticonsumption and sustainability-oriented practices (i.e., rejection, consumption reduction, and reuse of available products) are motivated by their individual needs and values including those pertaining to the well-being of the environment (Black and Cherrier, 2010).

Sheth et al. (2011) recently proposed the idea of mindful consumption, based on "consciousness in thought and behavior about consequences of consumption" (Sheth et al., 2011: p. 27). Mindful consumption involves caring about the implications and consequences of consumption and temperance in consumption behaviors. Particularly, mindful consumers care about themselves, nature, and their community and consequently are willing to modify repetitive, acquisitive, and aspirational behaviors that are hallmark of overconsumption (Sheth et al., 2011). In the interests of sustainability, Sheth et al. (2011) called for marketers to practice optimal marketing, which is the level where consumers' needs are optimally fulfilled, as opposed to overmarketing. These researchers note that shifting to mindful consumption may open avenues for new, profitable, business models such as those involving the sharing of products and services.

Connoting mindful consumption, and creative reuse, Walker, a journalist, used the term unconsumption to build excitement around repurposing old belongings (Pescovitz, 2011). Walker has defined unconsumption on his Tumblr blog in terms of "everything that happens after an act of acquisition" or "making things last, finding new uses for them; or when they're used up, getting rid of them in the most responsible way" (Unconsumption.org). Although the term has yet to gain traction among consumer researchers, the term unconsumer has been used in the marketing literature to refer to consumers who opt to simplify their lifestyles (Huneke, 2005). Through unconsumption, Walker attempted to brand consumers' responsible behaviors (i.e., alternative consumption, mindful consumption, anticonsumption, dematerialization, and collaborative consumption) in a way that they may garner added psychological value from their choices. In an interview, Walker stated, "Branding has been one of my main subjects...for a few years I've pondered if there's a way to borrow some of the tools of brand-making to advance an idea, but without actually creating products" (Gilleland, 2011). Walker's idea resulted in the creation of the $\mathrm{Mr}$ (or Ms) Cart, the unconsumption logo depicting a smiling, overturned, shopping cart, and of The Uncollection, an effort encouraging consumers to brand used items with the unconsumption logo as a way of upcycling, reusing, and prolonging the life of goods that they already own. A recent Google search on unconsumption (March, 2012) returned over 240000 search results, indicating that the term and its meaning is gaining online traction. However, the longer-term impact of this effort is yet to be seen. Nonetheless, the meaning attributed to unconsumption overlaps with other terminology in the literature, and, as such, we use the terms collaborative consumption and alternative consumption (which encompasses the former) in this research.

Although researchers have begun exploring formalized sharing from a consumer behavior perspective, much of this research is yet within the framework of monetary transactions and limited consumer interaction (i.e., consumer A subscribes to a sharing program and accesses the products and/or services through a centralized distribution center without significant interaction with coparticipants). Belk (2010) contended that by paying scant attention to sharing, researchers are committing a fundamental omission in their attempts to understand consumption. We address this gap through examining free-sharing events that foster sustainability practices and confer community benefits on different fronts from reduced environmental impact to consumers' enhanced sense of psychological well-being. As more entities, such as churches and universities, become involved in organizing free-sharing events, exploring this context affords an opportunity to further understand this phenomenon. Furthermore, consumers who participate in such events are indicative of future trends in consumer behavior, and studying their preferences and motivations would help prepare businesses, as well as other interested parties such as government agencies that engage in social marketing, to meet future demands.

We contribute to the literature in several ways. First, our study partially addresses Belk's (2010: p. 729) question, "What can be done to encourage prosocial sharing of. . .resources that are now used wastefully?" We also respond to Cherrier's (2009) call for further research on "how and why individuals resist particular consumption practices, who these individuals are, and the meanings they give to their participation." Second, we study collaborative consumption, in a context that does not involve monetary transactions and where participants freely interact with one another. We expect our research to yield insight on collaborative consumption beyond what is currently available in the extant literature because, to date, most studies of formalized collaborative consumption examine contexts that involve monetary exchange and 
minimal participant interaction. In addition, although some studies of the public sphere exist, for example, on flea markets (Belk et al., 1988; Sherry, 1990) and toy libraries (Ozanne and Ballantine, 2010; Ozanne and Ozanne, 2011), the majority of extant research on sharing is primarily focused on the intimate sphere of family and friends (e.g., Pavia, 1993; Price et al., 2000; Albinsson and Perera, 2009). Third, because the notion of community is at the core of collaborative consumption, including temporary sharing events, we use community theory as a lens to guide our research.

\section{LITERATURE REVIEW}

While people survive without communities, the thinner their community bonds, the more alienated and unreasoning they tend to be (Etzioni, 1996: p. 303).

\section{Community theory}

Although there is a lack of consensus in the literature on what constitutes community, Aristotle regarded it as the interdependence, and reciprocity, between diverse individuals (Selznick, 1992). Reciprocity, the belief that a favor today would be repaid by the receiver, or someone else, later, is one of the most discussed aspects with respect to community (Putnam, 2000). Gusfield (1975) differentiated between two forms of community: geographical and relational. Although the two are not mutually exclusive, the former pertains to the idea that a community exists within a particular locale, for instance, a city; the latter concerns human relationships regardless of location (Gusfield, 1975). For many researchers, community emphasizes relational aspects with, for instance, Durkheim (1964), noting that community is developed around skills and interests as opposed to geography. Along this vein, Wood and Judikis (2002: p.12) regarded community "as a group of people who have a sense of common purpose(s) and/ or interest(s) for which they assume mutual responsibility, who acknowledge their interconnectedness, who respect the individual differences among members, and who commit themselves to the well-being of each other and the integrity and wellbeing of the group." In the present, the tremendous popularity of online communities, based on common interests rather than geographical location, highlights the relational aspects of community.

Intuitively, with respect to the emphasis on the relational aspect of community, some scholars regarded networks in which individuals participate (Lee and Newby, 1983; Putnam, 2000) as being key to community. Our strongest connections are with family and friends; beyond this inner circle lays other groups and communities with weak ties including work, church, neighborhood, and other societal groups (Putnam, 2000). Within such a framework, individuals' community experiences may be explained by the quality of their networks such as the degree of connectedness, shared values, norms, and meanings (Etzioni, 1996). Norms or shared expectations of behavior, willingly abided by community members, often serve as the driving and binding force of community. With the different types of networks that exist in today's world, consumers often consider themselves as being members of multiple communities (Wood and Judikis, 2002).

The idea of networks and characteristics such as tolerance, norms, trust, and reciprocity connote social capital. Although many definitions exist, Putnam (2000: p. 19) defined social capital as "connections among individuals-social networks and the norms of reciprocity and trustworthiness that arise from them." Interactions between individuals must occur for social capital to exist. Interaction is also a key part of community building, which includes both tolerance and trust in others (Coleman, 1990; Putnam, 1993; Walzer, 1997). Society garners many benefits through developing networks, and social capital, such as civic engagement, economic prosperity, quality of public spaces, health, happiness, and decreased incidences of societal threats such as crime and poverty (Putnam, 2000). The next section focuses on collaborative consumption where consumer networks group together to resist traditional consumer culture with the aim of reducing levels of excessive material consumption.

\section{Collaborative consumption}

In 2011, Time Magazine named collaborative consumption, which entails renting, lending, and sharing of goods, as one of "10 ideas that will change the world" using the headline “Today's smart choice: Don't own. Share" (Walsh, 2011). Botsman and Rogers (2010) noted that, besides the obvious advantages, peer-to-peer collaborative consumption fosters community. However, collaborative consumption is not a new idea. In 1978, Felson and Spaeth spoke of collaborative consumption as "events in which one or more persons consume economic goods or services in the process of engaging in joint activities with one or more others" (p. 614). These acts include having beer with friends, and using a washing machine for family laundry, or sharing a car ride. However, it is doubtful whether Felson and Spaeth (1978) foresaw the extent to which collaborative consumption would be embraced and developed further in terms of new service and business models (Botsman and Rogers, 2010) that facilitate a simultaneous reduction in personal consumption (Sheth et al., 2011).

The first category of collaborative consumption includes product service systems where consumers pay a fee for sharing a given resource. Examples include Singapore-based Rent-a-Toy that allows parents to rent various, often expensive, toys for their children and clothing libraries that have recently opened in the Swedish cities of Umeå, Stockholm, and Malmö. The second category of collaborative consumption includes redistribution markets; large general marketplaces like eBay and Craigslist; specialized marketplaces such as Gazelle that focuses on used electronics; and Hey, Neighbor!, a neighborhood Facebook site that allows those living in particular locales to connect with each other and share resources and "microfavors." Redistribution markets include various swap sites such as Swapstyle and BookMooch, as well as free exchange sites including Freecycle and Freally, which allows for lateral cycling of used goods. The third 
category of collaborative consumption is collaborative lifestyles whereby consumers with similar interests are "banding together to share and exchange less tangible assets such as time, space, skills, and money" (Collaborative Consumption; justfortheloveofit.org). This category includes sharing of workspaces, gardens, skills, and parking spots. Examples include Web sites such as CouchSurfing and Airbnb through which travelers can find accommodations at other consumers' homes, grubwithus.com where strangers can meet to dine, and Justfortheloveofit.org's "the freeconomy community" whose goal is to connect people through sharing.

\section{Sharing}

On the whole, you find wealth much more in use than in ownership.-Aristotle

Sharing is a key element of collaborative consumption. Belk (2007: p. 126) defined sharing as, "the act and process of distributing what is ours to others for their use and/or the act or process of receiving or taking something from others for our use." Sharing occurs in multiple contexts, for multiple reasons, and with multiple outcomes. Acts of sharing emphasize joint, or perhaps serial, ownership and are distinct from gift giving and marketplace exchanges that stress private ownership of both tangibles and intangibles (Belk, 2007). As such, on a continuum, commodity exchange exists on one end, sharing on the other, with gift giving in the middle (Belk, 2007).

In the early exploration of sharing within small intimate groups, Price (1975) defined sharing as "the allocation of economic goods and services without calculating returns" that is "as much emotional as it is rational" with low formality and low need to acknowledge what is taken and given (p. 4-5). In contrast to economics-based marketplace exchanges, sharing connotes unequal exchange characterized by the sentiment of consumer A's ability to share and consumer B's need. Belk (2007) noted that, excluding immediate family members, consumers tend to share possessions minimally. However, widening of the sharing circle may occur if consumers' extended selves identify with those beyond their families (Belk, 1988; Etzioni, 1988). Consumers "circle of sharing" has recently expanded from one entailing primarily family and close friends to a public, communitywide circle facilitated by the Internet and various local and national organizations (Belk, 2007, 2010; Bardhi and Eckhardt, 2010; Ozanne and Ballantine, 2010; Ozanne and Ozanne, 2011). Widening the circle of sharing through identifying with others beyond one's immediate circle is aligned with the common interests and purposes of communities discussed in community theory literature (Wood and Judikis, 2002).

Although sharing behaviors are likely to have occurred for millennia in many global societies, the widespread use of the Internet and popularity of various platforms that facilitate the sharing of user-generated content, such as YouTube, has brought sharing to the forefront in current times (Belk, 2010). However, consumer researchers have paid minimal attention to sharing perhaps because sharing usually occurs in the intimate sphere as opposed to the public spheres of work and market. Moreover, sharing is often confused with gift giving and commodity exchange, and, because sharing is commonplace, it is often taken for granted (Belk, 2010). With the recent popularity of collaborative consumption efforts, it behooves consumer researchers to pay more attention to public-sharing-based models to elucidate what distinguishes such models from others. The following section discusses two sharing-based alternative marketplaces examined in the current study.

\section{THE STUDY CONTEXT}

\section{Sharing events (swaps)}

Organized sharing events, or swaps, are consumer-created alternative marketplaces that embody facets of collaborative consumption. The forms in which swaps manifest are based on the organizers' motivations and target participants' interests. Albinsson and Perera (2009) studied non-monetary clothing swaps as a form of voluntary disposition where friends and coworkers gathered to share gently used clothes and other goods without any monetary exchange. This phenomenon, which they posited to be a sharing network, is known as swapping in North America and swishing in the UK. With an explosion of websites that offer goods for swapping or purchasing either online or through specific events, swapping or swishing has become popular both on an informal and formal basis.

Although some events are free, others (e.g., Diva Eve Clothing Swap, Fashion Stimulus Clothing Swap) entail monetary exchange (e.g., prepurchase of tickets to the event and the possibility of purchasing the goods in lieu of swapping). These events emphasize a particular lifestyle and are often driven by the need to acquire goods at reduced cost and to limit wastefulness. Yet, other swaps seem to be driven by different motives such as decluttering, responsible disposition, and simplifying lifestyles. Examples of such sites include The Fashion Stimulus Clothing Swap where participants pay $\$ 30$ at the door and free offline events such as Kids Clothing Swap held in New York's Metropolitan Pavilion in 2009 or events organized by the S.W.A.P. Team based in Montreal, Canada. The Web is replete with advice on how to organize your own clothing swap or swishing party, with taglines such as "Detox your wardrobe by holding a swishing party. A group of fashion-hungry women, exchanging outfits on a guilt-free shopping trip!" (Hart, 2008) or "Raise money for your chosen charity with an ethical clothes swap event and help your friends declutter and recycle their wardrobe for a great cause" (Hegarty, 2010).

\section{Really Really Free Markets}

Similar to Freecycle, the online site that provides free goods and services, Really Really Free Markets (RRFM) and other comparable events are composed of consumers who gather to form temporary marketplaces with underlying alternative consumption logic (CrimethInc). The RRFM model was initially developed by the Anarchist Movement that identifies with a "social situation free of government and coercive hierarchies held together by self-organized horizontal relationships," emphasizing the core belief that people know 
how to live their own lives without expert intervention (Gelderloos, 2010: p. 4). These alternative markets were organized to counter exploitation and domination implicit in traditional capitalist market systems by encouraging consumers to share their excess goods. The first RRFM events occurred simultaneously in Miami, Florida, and Raleigh, North Carolina in 2004 when the anarchist network protested the G-8 summit (Simpich, 2004). According to lore, RRFMs were staged when the anarchist protestors were asked to clarify what they believed in as opposed to what they were against.

As the name suggests, everything at an RRFM and similar sharing events is free, irrespective of whether the participants bring anything to share. Leftover items are traditionally donated to shelters and other charity organizations. The consumers who participate in such gatherings are either motivated by global-level societal concerns or they are personally motivated simplifiers who aim to reduce general consumption (Iyer and Muncy, 2009). This movement has spread across the USA and Canada (both in the form of one-time events and routinely scheduled events) to other countries including Russia, Taiwan, and the UK (The Really Really Free Market).

Although there is much diversity within the "sharing realm," we focus our attention on North American private and public sharing events, including RRFMs. These events, compared with those that primarily emphasize material goods and financial benefits, appear to integrate sustainability ideology and resistance to traditional marketplace structures. As the context of RRFMs and sharing with no monetary exchange has received limited scholarly attention from a consumer behavior perspective, we believe that the unique aspects of this particular context could potentially enlighten us further about consumer-driven alternative marketplaces.

\section{METHOD}

Through purposive sampling (Glaser and Strauss, 1967; Lincoln and Guba, 1985), our informants are composed of RRFMs and other sharing event organizers and participants. We attended five public and four private non-monetarybased sharing events and initiated informal and formal interviews during May 2009-July 2011. Data collection occurred through participant observation, 10 formal in-depth interviews, and 36 informal unstructured face-to-face and Skype interviews (Ballantine and Creery, 2010). Five events were organized in public places (parks, churches, and university facilities) in the southeastern part of the USA and were advertised via e-mail, sandwich boards, banners, and flyers throughout the local communities in which they were held. Everyone was welcome to these events; membership in a specific organization or community was not a prerequisite for attendance. We were invited to the four private events, staged in participants' homes, through their conversations at the public events. Before each event, the researchers informed organizers of their research project and received permission to observe the events and conduct interviews. The unstructured informal interviews were conducted to obtain a greater understanding of the phenomenon and to prepare our final interview protocol. We obtained informed consent from the participants for the formal interviews.

The formal interviews began with grand tour-like questions (Spradley, 1979) where participants spoke of their broad experiences before responding to more probing questions. The interviews, approximately 45-75 $\mathrm{min}$ in length, were digitally recorded and transcribed by one of the authors. The unstructured interviews, lasting approximately 5-15 min, with participants at the RRFMs or sharing events were not recorded due to high levels of background noise and other distractions. Instead, the author who attended the events wrote immediate field notes on each informal interview and on each observed event shortly thereafter. Some of the broad questions that guided our interviews were as follows: Why do consumers band together to popularize alternate forms of consumption? Why do consumers care about community well-being? How can consumers trust that their needs are met and that they are treated fairly while ensuring that others' needs are also respected and met?

Seven women and three men, varying age from 22 to 51 years, participated in the formal interviews. All were current participants of sharing events, and some were organizers and avid advocates of collaborative consumption. Although the initial RRFMs in 2004 were staged by the Anarchist Movement, none of our participants identified strongly with the term anarchist and were uncomfortable with labels such as activist, radical, etc. However, most informants strongly identified with the sustainability movement and participated in various efforts to further this cause and other means of societal well-being.

We followed qualitative and hermeneutic data analysis processes using iterative readings of transcribed interview data and field notes from participant observations. The researchers initially reviewed and coded the transcribed data independently and later discussed the coding to identify emergent global themes. For analysis purposes, per standard grounded theory procedure (Glaser and Strauss, 1967), the researchers initially labeled the data paragraph by paragraph (based on responses to individual questions) through open coding and subsequently collapsed the codes into categories and finally into themes.

\section{FINDINGS}

Shared consumption is critical to offset, and eventually replace, models of individual consumption that lead to "hyperconsumption" and its unsustainable consequences. From swaps and shared wardrobes to community libraries, public transportation, and potlucks, sharing the things we need can lessen our environmental impact and increase our community's health.-Kelly

As Kelly's quote vividly illustrates, our findings indicate a consumer-driven desire to enact social change while fostering personal and community well-being through participation in 
alternative marketplaces. In the dominant economic and exchange-based marketplace, consumers exchange a combination of time, money, and effort to obtain a service or good from a seller. However, we find that many consumers deliberately engage in alternative consumption, with their families, friends, and even strangers, through upcycling, reducing, reusing, recycling, repairing, and redistributing possessions through sharing, donating, and ridding (i.e., throwing away) (Albinsson and Perera, 2009; Nelson and Rademacher, 2009; Botsman and Rogers, 2010). As such, with the rise of these private and public virtual and physical space-oriented alternative marketplaces, our analysis indicates that the nexus of value has expanded to include not only the goods and services but also the interactions between the individuals who participate in the giving and receiving.

\section{Beyond goods: The sharing of skills, knowledge, space, and ideas}

Sharing of skills, goods, and more

Although sharing events deal mostly in tangible items such as apparel, electronics, and furniture (see Appendix, photo 1), our informants enthusiastically described the various intangibles that are also shared. Megan, a 26-year-old graduate student and a member of several local community groups, has participated in organizing seven RRFMs over a 5-year period. An avid supporter of sharing, Megan noted that participants sometimes share their skills with others through services such as henna and face painting, haircutting, massage, juggling, and lawn services. This form of engagement clearly "shows participants that even if they didn't have any materialistic stuff to share, they could still participate" in the sharing event. Another informant, Allison, a 33-year old who had organized six and participated in 20 sharing events is "passionate about abating the harmful ecological impacts of human consumption." She noted,

I have always enjoyed when people brought things to share that weren't expected or traditional-puppet shows, music, a talent or skill to share and teach-or when the events turned into places to network, to have an impromptu dance party, or to nap in the sun...Really Really Free Markets. . .are simultaneously relaxing and exciting and always warm and open. Where else can you find a tutu making workshop, a place to play soccer, lively book discussions, and people eating free food in the sun?

In terms of outreach, some organizers felt that sharing events were alien to the general person walking along a main street or the sidewalks of a college campus. However, if the sharing events were affiliated with a certain social group that was recognizable, or if the participants were doing something that seemed ordinary, passers-by were more apt to participate even if they were unfamiliar with the context. As Allison further shared,

One group I was involved with used to have what they called an anarchist library; books were available to the public, so it was sort of an information swap. That is, people were given access to reading material without requiring a library card or by having a permanent address. We just set up at corner of a parking lot so that we utilized public space, and anyone walking by could participate.

\section{Raising awareness and support through collaboration}

At times, various community groups, whose primary focus lay beyond the sustainability and responsible consumption arena, organized sharing events as a means of supporting their primary constituents. For example, on one campus, several sharing events were organized by TransAction, a university-based transgender peer group that focused on "deconstructing the gender binary." TransAction organized the events in collaboration with a Pride Festival (celebration of gay, lesbian, bisexual, and transgendered individuals and their allies) to raise awareness on gender-diversity-related issues. Kelly, a 25-year-old woman who had helped organize 10 sharing events and RRFMs in both small towns and large cities such as Detroit and New York City, recalled the supportive and practical nature of one such event,

That one was pretty great. ..we got a lot of different folks together, so you had folks bringing the clothes that they weren't comfortable wearing anymore and exchanging with other people who were doing the same...males transitioning into females getting rid of all their masculine clothes. . females who wanted male clothing were able to scoop those up and exchange their feminine clothes... Changing out a whole wardrobe is an expensive process, and these events facilitated many through this process.

Besides offering an emotionally warm space for consumers to gather and share tangibles and intangibles, various formal organizations used these events for raising consumers' awareness of issues. For instance, at one event, the representatives of several local organizations (e.g., those supporting individuals with substance abuse issues) educated participants on their work in the community. At several others, the local university and city waste management personnel distributed recycling bins and brochures on disposing of dangerous goods. Such "official capacity participants" raised community awareness through educating interested sharing event participants (see Appendix, photo 2). Megan noted,

We also had recycling representatives... assisting people coming in and saying, "Where do I recycle my old tires?" It wasn't all about the swap...it was definitely about sharing information and building awareness as well as a swap. Taking advantage of the fact that people may not know things and trying to change that...we brought in rigid plastic items to show that we now can recycle these on campus and in the community.

However, although the sharing events included such educational opportunities, the broader purpose was to educate participants on alternative marketplaces. As Kelly noted,

There's definitely education about recycling and reuse... but it was more about sharing space and sharing resources and sort of demonstrating an alternative model to monetary exchange. 
Besides collaboration through staging RRFMs and sharing events in conjunction with others, organizers supported community entities in other ways. Shelters, medical clinics, and churches typically need food, medicine bottles, shoes, and apparel to serve their clientele. At one RRFM, the organizers alerted participants that jackets, coats, and other winter clothes were being earmarked for a local coat drive. As such, unless the participants truly needed winter clothes, they were asked to forfeit acquiring them to donate them to people with more urgent needs. We also found that swap organizers often collaborated with churches and community organizations by utilizing their space to stage the sharing events. These instances of cooperation created win-win outcomes for all concerned.

The importance of common shared space and the idea that sharing encompasses goods, services, and ideological space surfaced in our conversations with informants. Creating exclusive communities, intentionally or otherwise, is detrimental to the spirit of alternative marketplaces and sustainable consumption because they are based on the idea of consumers working together for societal well-being. Thus, being inclusive through collaboration and staging these events in public spaces communicated the message of "common space, common goods," thereby attracting more curiosity and participation. This meant that participants with different beliefs, or different degrees of beliefs, interacted within this space and had opportunity to share and broaden each other's perspectives as they engaged in sharing.

\section{Sharing and fostering new ways to consume through community building \\ Community building}

Sharing events as a means of community building was another emergent theme. According to Allison,

Sharing is an often neglected and undervalued act in capitalist societies... .Our current economic system feeds on profit and thus relies on individual ownership. . .dividing individuals in the hopes that more will be sold if no one shares. . .individualism tears apart the fabric of communities, which rely on shared interests, and promotes selfcenteredness across many fronts...millions of individual cars polluting the environment, and a ton of individual yogurt containers in landfills or to be recycled.... When we have community, we have fulfillment in one another, mutual aid and support, and caring neighbors to depend on. Without community, we are isolated beings, disconnected, and unable to resist oppression collectively or to unite towards common goals... .I wanted to create a space where people could meet and mingle, have discussions or play or unwind, and find the things they needed without having to pay or bring anything in return. In this way, Really Really Free Markets fill needs that money can't buy.

Allison's passion for community building and her desire to encourage alternative consumption and sharing are clearly communicated through her statement. She highlights the importance of a cohesive social fabric, the need to create social capital among individuals and communities, and her vision for how RRFMs could contribute to this cause. Kelly shared a similar sentiment:
It's really important to reconnect with our communities... sharing is such a fundamental, simple way to do that. Some people have like big radical politics about it, like take down capitalism and all that, but RRFMs wouldn't exist without a capitalist system, you know, like we've got excess because we live in a system that promotes excess. For me, it's just simply about sharing and reconnecting and creating value outside of monetary value.

Melissa, a 51-year-old participant, spoke of the beauty of RRFMs and other sharing events in terms of how they helped some clean out their unwanted possessions responsibly and allowed others to find exactly what they needed. Interestingly, items acquired through free-sharing events continued to change hands postacquisition. For example, two weeks after an event, one informant passed on some of the items she had acquired to others in her network; the new owners were excited by the "new" additions to their wardrobes. With each change in ownership, an object is "renewed," lending credence to the idea that our possessions have a life apart from us. Although we own certain possessions at a particular time, if we understand that our possessions may have useful lives beyond their usefulness to us and share them with others, we widen the circle and pleasure of ownership and the utility of the object. Albinsson and Perera (2009) found that participants' perceptions of their possessions transformed from "mine to ours" in clothing exchange contexts. This shift in how the participants view ownership resulted in some participants bringing back some items they had previously claimed but decided they did not like or simply had not used to subsequent sharing events so that others could gain pleasure and use from them.

\section{Sharing as caring}

Many first-time participants of sharing events, both private and public, were surprised by the absence of price tags and cashiers. When told that the items are free, "no strings attached," many of these consumers were hesitant and had a difficult time accepting that the items were completely free for the taking. Sara, a new organizer and avid proponent of sustainable consumption, recalls one particular interaction with a participant:

This one woman...walked up with her daughter and was like "what is all this stuff?" and I'm like "oh it's a free market so you can just have any of the stuff that you want," and she's like "what's the catch?" and I was like "there's no catch, this is stuff that people don't need anymore that they've brought that you can have." She's like "who benefits?" and I was like "right now you and I benefit, because we're interacting with each other and we probably wouldn't have, and we've come to this park, and you are getting to use things that normally would be thrown away"... and she thought about it. . .like, stood there and looked at me and kept thinking about it and then she sat down in the grass and started trying on shoes like it was the best day ever.

Consumers expect to give up something to acquire what they want in the marketplace. Event organizers constantly 
challenge this norm by informing new participants and curious passers-by that it really is okay to take more than you leave or take something without giving anything in return. This alternative marketplace, where consumers offer their fellow consumers goods and services without any specific guidelines other than everything is up for grabs, illustrates a new way to consume in modern societies. We observed a genuine care for others in our dialogue with the informants. Oftentimes, the goods at sharing events simply serve to convene consumers for interaction and fostering relationships. This is a point of attraction for those who enjoy this sharing and caring approach to life. However, others, who find the emphasis on the relationship aspect less attractive, may choose to participate for other reasons. For example, Simon, a 29-year-old male informant, who frequently participate in sharing events, noted,

Some of my favorite things I have acquired at swaps; just because they were free doesn't mean that they mean less to me. Sometimes, I feel the opposite, I feel grateful that someone else were ready to part with the item so I could benefit from it.

In this case, Simon appreciated the fact that others were willing to share their possessions with him through these events. As such, besides procuring various needed items, he perpetuated the cycle of sharing and goodwill by sharing his possessions so that others could benefit from his participation.

\section{Reciprocity and getting our fair share}

Sharing events come in all shapes, forms, and sizes. A primary distinction between RRFMs-type sharing swaps and more commercially oriented organized events is the notion of value exchange. Sharing events where each participant receives a ticket for each item he or she brings appeal to the larger capitalist culture that emphasizes "getting one's fair share." This notion is so pervasive that, as noted earlier, it is sometimes difficult to persuade consumers who did not bring anything that they still deserve to share the items and services provided. RRFMs emphasize generalized reciprocity (Nelson and Rademacher, 2009) or what Belk (2010) calls non-reciprocal behaviors, where consumers give without the expectation of anything in return. As Kelly said,

We are brought up with ideas of reciprocity, and we feel guilty for not giving something in return. We try to challenge this by saying, you benefit from this today... another time you can share or pay it forward...I guess with the sense of creating more intimate interactions between strangers. I mean no one would question giving their cousin all the clothes in their closet if they needed it, right? But if it's a stranger, you expect to get something back. We need to change this.

Kelly gets at the heart of Belk's (1988) work that examines the notion of extended self. Belk (2010) posited sharing in as intimate sharing where others are encompassed within one's idea of extended self and sharing out as sharing with those outside one's notion of self. Many informants were familiar with other sharing event participants through their prior experiences in staging and participating in these events. These individuals appeared to have a sense of community with one another, and their sharing may be construed as sharing in with individuals with whom they identify. Yet, others, who were new to the context, often felt the need to reciprocate when taking an item, thus indicating that they maintained a separateness from others at the event. Thus, their participation may be regarded as sharing out. Sharing event organizers faced challenges in shifting consumers' deep-seated perspective that the right to take something is only granted if one contributed something in return. In our informal conversations and participant observations, we noted a strong need to reciprocate on the part of some consumers who were either grateful to acquire something they needed or uncomfortable to take something for nothing. These individuals inquired whether they could leave something they had on hand behind and added items such as pens, key chains, and snacks to the communal sharing pile. Sharing events strive to unfix this market-based mentality by educating, raising awareness, and demonstrating caring and community on many different levels (see Appendix A, photo 3 ).

In summary, the sharing events challenged many newcomers' perceptions of what a marketplace entails. Some of the organizers had to educate these consumers and persuade them that taking without giving was acceptable in this context. Others used this as an opportunity to discuss challenging aspects of the market-based economy where prices are artificially inflated in the name of profit. On another and perhaps more subtle level, educating newcomers about the logistics and expectations of the swap meant that the organizers were implicitly "teaching" these individuals about generosity, responsibility to one another, and thankfulness in some respect. With the advent of money-based sharing sites such as Craigslist and eBay, many participants could have sold their items online to earn money. However, for a variety of reasons, they chose to share their items and acquire others through sharing. As such, educating newcomers about alternative marketplaces expands routine ways of thinking about markets and the value of items.

\section{DISCUSSION}

Our research, examining private and public sharing events that fall under the second category of collaborative consumption described by Botsman and Rogers (2010), extends our understanding of collaborative consumption and alternative consumption. For participants, these sharing events represented a range of meanings from political statements, to a desire to help specific groups (e.g., to help transgendered consumers acquire a new wardrobe), to a venue for educating the public on sustainability. By coupling education with actual enactment, organizers helped consumers practice socially responsible behaviors. 
The broad emergent themes emphasized the importance of community. Our informants described how participating in these events helped them feel more involved with others in the broader community. Wood and Judikis' (2002), who did not specify any particular timeframe a community must exist to be considered as such, noted that a community does not exist in the absence of purpose, interconnectedness, and individual investment. Besides being venues for responsible disposition and acquisition, sharing events are convened to share broader messages on sustainable consumption, political ideology, and other social issues. These causes ranged from political activism, economic activism, supporting transgender communities, raising environmental awareness and promoting recycling, and reusing goods. Thus, despite the temporary nature of these events, and the limited awareness of newcomers, we contend that these events constitute communities, albeit momentary. We observed significant effort on the part of organizers, and seasoned participants, to create a community feel at these events by reaching out to participants to foster a welcoming atmosphere, educate them on the norms of the context, and advocate the particular cause being supported. Organizers coached participants in the sharing process as these sharing events represented a new context where many participants had to reconsider their typical acquisition and disposition behaviors. The organizers' behavior is consistent with community theory with respect to how communities educate members and nonmembers (Wood and Judikis, 2002). Therefore, the events clearly serve as spaces for raising awareness and broadening perspectives on social issues, which mirror Mathews' (1996) idea of community as diverse individuals gathering to improve their mutual well-being.

Most sharing communities reflect Price's (1975) definition of sharing that emphasizes a low need to acknowledge what is taken and given. However, some participants struggled to accept free goods, whereas others were comfortable with doing so. The reluctance could be attributed to societal messages on what it means to take more than to give based, for instance, on cultural norms (Albinsson and Perera, 2009) or social class, or perhaps consumers find it difficult to accept free items because the only goods acquisition systems they know of is the traditional market system where one pays for goods and services acquired. Changing consumers' mindsets requires the adoption of a longer term perspective that views consumption and disposition as a series of events through the course of one's existence and not as one-time events. Thus, sometimes, consumers will take more than they give, but at other times they will contribute more to the collective well-being. This mindful approach to consumption becomes a nexus for relationship building within a community where shared goods become ours before they are redistributed to new owners. This point about degree of comfort in sharing also brings up the notion of extended self (Belk, 1988, 2010) with participants who had incorporated the idea of the sharing community as a part of their extended self being more comfortable with sharing and taking items.
Branding responsible consumption behaviors as unconsumption (Walker, 2007) surfaces the question of what entails value within alternative marketplaces. Traditionally, the notion of exchange was the core component of marketing (Alderson, 1957; Kotler and Levy, 1969; Bagozzi, 1975; Sheth and Uslay, 2007). Within each exchange, we find utilitarian (economic value), symbolic (mutual psychological, social, and other benefits), or mixed meaning (Bagozzi, 1975). Researchers maintained that sharing is not exchange (e.g., Price, 1975), and viewed from a marketplace exchange perspective, direct economic-based value is not apparent in these sharing events. According to Bagozzi (1975), a utilitarian exchange involves the exchange of goods for money or other goods motivated by the value or anticipated use of the objects exchanged. In the studied context, the direct utilitarian value is absent because participants contribute their tangibles and intangibles to a shared pool from which they, and others, can draw to fill their respective needs. As such, in this particular context, utilitarian value is very much dependent upon the behaviors and motives of consumers who participate. However, symbolic value in terms of feeling good about participating in such events, not only through sharing goods but also through supporting a particular ideology, is definitely present in this context.

Overall, our findings, which indicate that consumers value forming connections with their friends, family, and likeminded strangers, are supported by others advocating similar ideas. For example, Schor (2011), in discussing a new economic model, noted that citizens of countries such as the Netherlands, where people spend less time working due to fair distribution of work, consumers have time for more do-it-yourself projects that can translate into small-scale production and start-up businesses focusing on social innovation. Although such efforts yet occur on a miniscule scale relative to traditional-market-based consumption, we believe that the movement of consumers convening to share their possessions and skills through alternative marketplaces like RRFMs is a step towards creating social connection and community, which could potentially lead to healthier consumers, communities, and economy in the long term.

\section{Future research}

With the rising popularity of sharing events, we see the need for infrastructure that facilitates the establishment of permanent sharing facilities. Research indicates that local infrastructure plays an instrumental role in consumers' disposition behaviors (Darby and Obara, 2005). Albinsson and Perera (2009) found that consumers' decisions to participate in responsible disposition practices were significantly influenced by availability of necessary infrastructure. Thus, the availability of a permanent sharing facility or the staging of periodic swaps within a community means that the "local infrastructure" is available for consumers' use. In the current climate, where it is important to educate and persuade consumers to adopt socially responsible practices as they affect our collective public goods (i.e., the environment), this finding is hopeful because it indicates that partnerships 
between various organizations to provide the necessary infrastructure may influence consumers to acquire and dispose of their possessions in a responsible manner. Future research could examine permanent facilities and programs that foster sharing and their effect on the communities. Examples include North Carolina's Warren Wilson College's Free Store, a storefront stocked with goods donated by university members that are, in turn, available to the campus community, and sharing programs such as universitysponsored ride and car sharing programs.

From a different vantage point, scholars have noted the influence of consumers' values with respect to their willingness to adopt responsible consumption behaviors (e.g., Black and Cherrier, 2010). Schwartz (1994), who focused on the individual and not societal level, defined values as "desirable transsituational goals, varying in importance, that serve as guiding principles in the life of a person or other social entity" (p. 21). Situating competing values on two bipolar dimensions, the first dimension is composed of values that foster independence and propensity for changing the status quo and those that preserve stability and tradition (Schwartz, 1994). The second dimension entails values that foster personal success and dominance over others and values that regard others as equals and exhibit concern for their well-being. Future research could explore the value configurations of sharing event participants. For example, it is possible that consumers who regard their participation as a means of furthering responsible consumption in society hold self-transcendence (i.e., universalism and benevolence) and openness to change (i.e., self-direction and stimulation) values that fuel their involvement. This, along with how to engage consumers with individualistic-oriented self-enhancement values (i.e., power and achievement) in collaborative consumption efforts, is fodder for future research.

In addition, although individuals with prosocial values may be partial to sharing efforts, others may have less altruistic, more self-oriented values that may be cause for concern in fostering free-sharing events. For example, a local Freecycle community reported that individuals were selling donated items. Such behaviors caused much consternation within the community as participants felt that their trust was violated. Such a situation could easily arise within the context of sharing events. Although one may contend that what an individual does with the goods he or she acquires at free swap events is a personal issue, participants nonetheless bring goods to share trusting that they will be used to directly fill other consumers' personal needs. Violation of this expectation is likely to impact participants' desire to engage in such efforts, and event organizers must pay attention to such concerns. However, we note that this is a complex issue on multiple levels. There is the argument of, if one has no expectations of reciprocity, why should local sharing communities ostracize consumers' suspected of using the free goods for purposes other than personal use, especially if such individuals are in need of money? The counterargument, of course, is that such behaviors violate sharing communities' values and norms. Nonetheless, it presents an area for future research.
Another alternative consumption practice that warrants more research is freeganism, which entails consumers' recovering food and other "perfectly good" products from garbage containers for consumption. Researchers could explore whether dumpstering (i.e., dumpster diving or skipping in the UK) is stealing or whether it is responsible consumption and redistribution on the part of consumers who redress the irresponsible behaviors of businesses that discard products that are yet fit for consumption. In terms of businesses, researchers could also examine what responsibility big box retailers and luxury brands have to society when they go about maintaining brand value by destroying unsold merchandise.

\section{CONCLUSION}

The past decade and a half has seen the rise of various consumer movements that address overconsumption. Besides focusing on reducing consumption, and fostering responsible consumption, the spotlight has also focused on considering the "whole" life of a product. A part of this involves careful consideration of disposition choices, redefining what constitutes trash, reusing, repurposing, and sharing existing products to extend their usefulness. Our study on collaborative consumption and alternative consumption within the context of sharing events addresses questions raised by scholars about sharing and why consumers resist certain consumption practices.

Through our observations of, and interviews with, participants and organizers of sharing events, we connect the act of sharing to both community building and alternative consumption to deepen our understanding of the complexities and challenges of collaborative consumption and sharing. Although our chosen context and qualitative research methods limit generalizability of our findings, we contribute to the literature on alternative consumption and sharing in several ways.

Sharing events serve as meeting spaces for individuals with different backgrounds, interests, and motives for participation. Although some were attracted to the responsible disposition and acquisition aspect of these events, others came to support various social causes or to enjoy the warm atmosphere of the events. We observed an intense desire to foster community building, stemming from consumers sense of lack of community in today's society. We also note that although sharing events should fall into the nonreciprocity realm, many consumers struggle with this idea. With new sharing business models surfacing in the marketplace, (e.g., Netflix, clothing and toy libraries), we may begin to observe an increase in dialogue pertaining to the need for establishing a greater sense of community from consumers, marketers, and policy makers. Although sharing businesses are still a small part of the economy, consumers readily participate in such models and other opportunities for sharing. Gansky (2010) suggested that big box retailers could learn from sharing-based business models (e.g., Netflix) by providing more serviceoriented offers, indicating that sharing, framed within the context of viable business models, is indeed moving from alternative marketplaces to the mainstream. 
The consumer initiatives such as alternative marketplaces and various other anticonsumption activities aim to extend the life, use, and value of goods while discouraging the acquisition of new purchases. Mirroring the ideas of transition initiatives, Prothero et al. (2011: p. 36) stated, "By shifting the paradigm away from individual ownership to collectivity and sharing, less demand for consumer goods may give way to a new economy that could help take on problems such as pollution and excessive energy usage." Through participating in alternative consumption efforts, consumers are likely to garner some measure of psychological well-being by contributing to something positive in their local communities. As a participant noted, "consider sharing, gifting, trading, swapping, donating, or lending things you have just lying around....Eventually, if we work together, we may be able to consume sustainably."

Besides community building on a local level, by staging sharing events, the organizers protest against hyperconsumption for the sake of community and environmental wellbeing. This is important as society has become increasingly "marketized," with politicians, for instance, referencing citizens as consumers (Prothero et al., 2011). For example, President Bush in introducing his 2008 stimulus package encouraged American citizens to increase their consumption for the sake of the economy. The emergent concept of consumer-citizens who are altruistic and embrace values such as constraint, moderation, and community interest (McGregor, 1999) is important for our discussion of consumer-driven sharing. We posit that sharing event organizers, due to their efforts in developing alternative marketplaces, fall under the category of consumer-citizens. In alignment with the consumer-citizen concept, a small minority of consumers are nonetheless increasingly assuming some measure of responsibility for developing a sustainable future. They are taking matters into their own hands by working with local governments to implement local laws and restrictions to foster sustainability. For example, such initiatives include local communities using their own currencies, banning certain material from landfills, and using methane gas from local landfills for heating businesses and as alternative energy to lessen the impact on the environment. Through such measures, pioneering consumer-citizens model to their fellow citizens how they too can collaborate to integrate the sustainability ethos into their lives and communities, thereby redefining consumption in the 21 st century and beyond.

\section{BIOGRAPHICAL NOTES}

Pia A. Albinsson, $\mathrm{PhD}$ (New Mexico State University), is an assistant professor of marketing in the Walker College of Business at Appalachian State University. Her research interests are in the areas of advertising rhetoric, advertising effectiveness, community networks in social media, socially responsible (corporate and consumer) behavior, and green consumption practices. Her work has been published or is forthcoming in the European Journal of Marketing, Journal of Consumer Behaviour, Journal of Public Policy and Marketing, Journal of Applied Business and Economics, Journal of Online Learning and Teaching, Academy of Educational Leadership Journal, and Advances in Consumer Research.

Yasanthi Perera is a doctoral candidate at the New Mexico State University. Her broad research interests encompass social entrepreneurship and social responsibility at the individual and organizational levels, with her dissertation examining value creation in for-profit social enterprises. Her other research includes works on sustainability education, assessment of value cocreation, and the influence of social media on consumer activism and firms' practices. Yasanthi has presented at numerous conferences and has been published in various journals including the Journal of Consumer Behaviour, Journal of Online Learning and Teaching, and the International Journal of Innovation and Learning.

APPENDIX

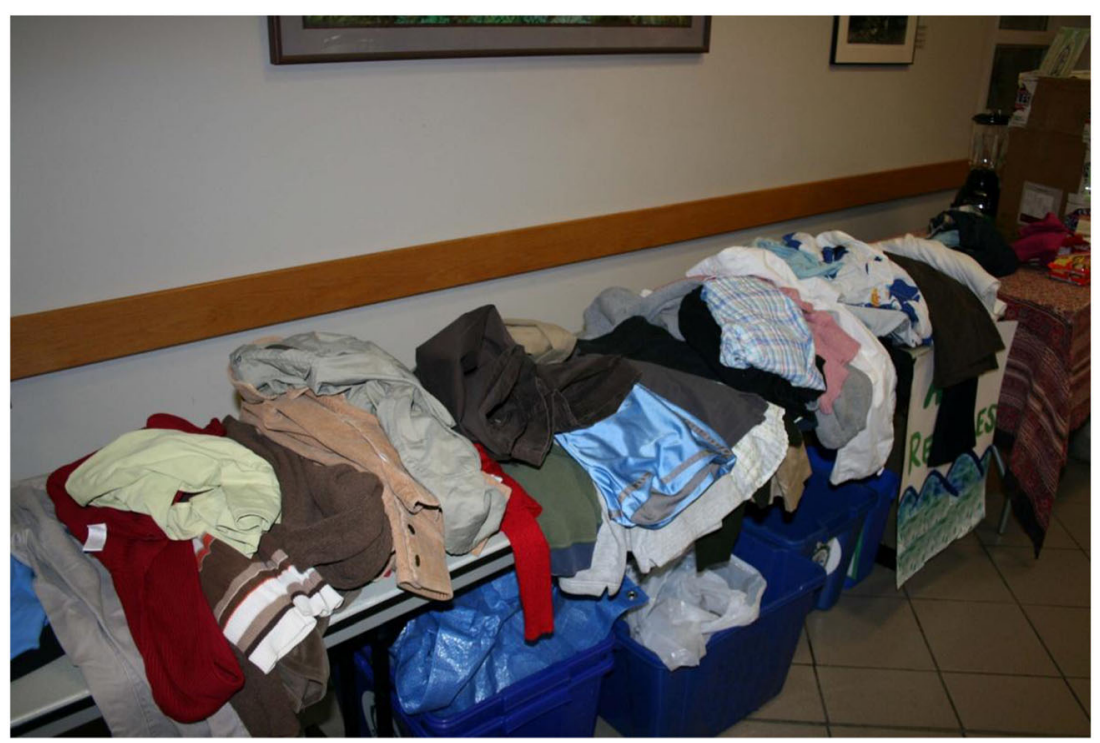

Photo 1. Used items and clothes at an RRFM. 


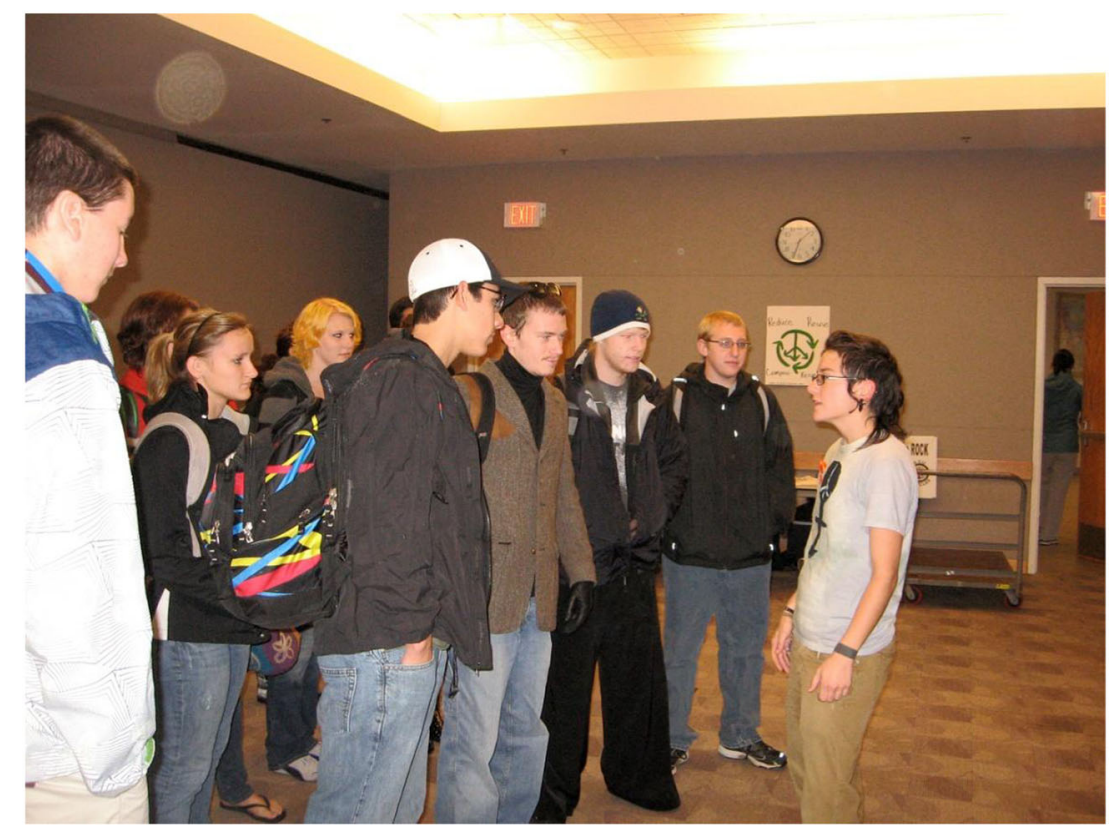

Photo 2. An organizer educating event participants on sharing and waste reduction.

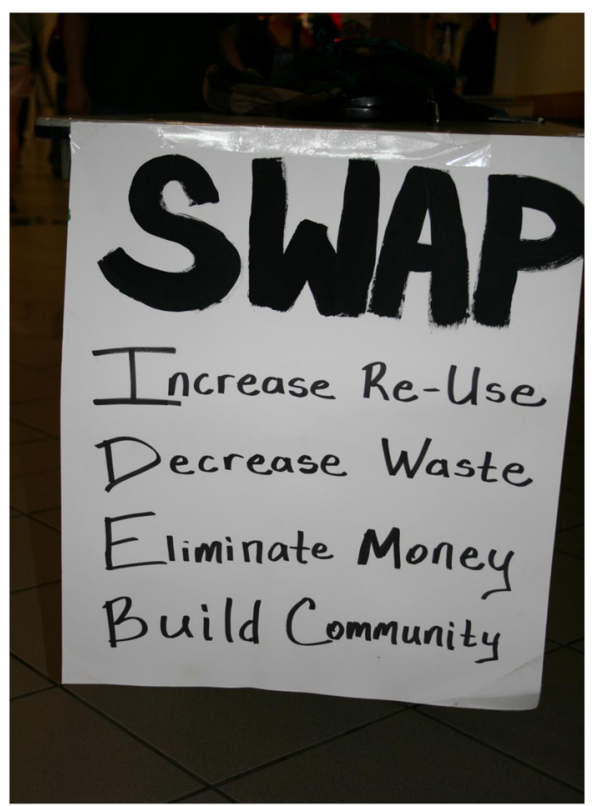

Photo 3. Sign at RRFM promoting unconsumption.

\section{REFERENCES}

Albinsson PA, Perera BY. 2009. From trash to treasure and beyond: the meaning of voluntary disposition. Journal of Consumer Behaviour 8(6): 340-353.

Albinsson PA, Wolf M, Kopf D. 2010. Anti-consumption in East Germany: Consumer resistance to hyperconsumption. Journal of Consumer Behaviour 9(6): 412-425.

Alderson W. 1957. Marketing behavior and executive action. Richard D. Irwin: Homewood, IL.

Arsel Z. 2010. Exploring the social dynamics of online bartering. Advances in Consumer Research Volume 37: 3-4.

Bagozzi RP. 1975. Marketing as exchange. Journal of Marketing 39(4): 32-39.

Ballantine PW, Creery S. 2010. The Consumption and disposition behaviour of voluntary simplifiers. Journal of Consumer Behaviour 9(Jan-Feb): 45-56.
Bardhi F, Eckhardt G. 2010. Market-mediated collaborative consumption in the context of car sharing. Advances in Consumer Research 37: 4-5.

Belk RW. 1988. Possessions and the extended self. Journal of Consumer Research 15(September): 139-168.

Belk R. 2007. Why not share rather than own? The Annals of the American Academy of Political and Social Science 611: 126-140.

Belk R. 2010. Sharing. Journal of Consumer Research 36(5): 715-734.

Belk RW, Sherry JF, Wallendorf M. 1988. A naturalistic inquiry into buyer and seller behaviour at a swap meet. Journal of Consumer Research 14(March): 449-470.

Black IR, Cherrier H. 2010. Anti-consumption as part of living a sustainable lifestyle: daily practices, contextual motivations and subjective values. Journal of Consumer Behaviour 9(6): 437-453.

Botsman R, Rogers R. 2010. What's mine is yours: the rise of collaborative consumption. Harper Business: New York, NY.

Cheetham F. 2009. Out of control? An ethnographic analysis of the disposal of collectable objects through auction. Journal of Consumer Behaviour 8(6): 316-326.

Cherrier H. 2009. Anti-consumption discourses and consumerresistant identities. Journal of Business Research 62(2): 181-190.

Coleman JC. 1990. Foundations of Social Theory. Harvard University Press: Cambridge, Massachusetts.

CrimethInc. Ex-Workers Collective. The Really Really Free Market: Instituting the gift economy. Available at http://www.crimethinc. com/texts/atoz/reallyreally.php [accessed on 29 August 2011].

Darby L, Obara L. 2005. Household recycling behaviour and attitudes towards the disposal of small electrical and electronic equipment. Resources, Conservation and Recycling 44(1): 17-35.

Denegri-Knott J, Molesworth M. 2009. 'I'll sell this and I'll buy them that': eBay and the management of possessions as stock. Journal of Consumer Behaviour 8(6): 305-315.

Durkheim E. (1964/1893). The division of labor in society. Free Press of Glencoe: New York, NY.

Etzioni A. 1988. The moral dimension: Toward a new economics. Free Press: New York, NY.

Etzioni A. 1996. Positive aspects of community and the dangers of fragmentation. Development and Change 27: 301-314.

Etzioni A. 2009. A new social movement? In Voluntary Simplicity: The Poetic Alternative to Consumer Culture. Stead \& Daughters Ltd: Whanganui, New Zealand; 55-73. 
Felson M, Spaeth J. 1978. Community structure and collaborative consumption: A routine activity approach. The American Behavioral Scientist 21(4): 614-624.

Gansky L. 2010. The mesh: Why the future of business is sharing. Penguin Groups: London.

Gelderloos P. 2010. Anarchy Works. Ardent Press: San Francisco, CA.

Gilleland D. 2011. The uncollection: giving new identity to stuff you already own. Available at blog.craftzine.com/archive/ 2011/06/the_uncollection_giving_new_id.html [accessed on 10 December 2011].

Glaser BG, Strauss AL. 1967. The Discovery of Grounded Theory: Strategies for Qualitative research. Aldine de Gruyter: Hawthorne, NY.

Gusfield JR. 1975. The community: A critical response. Harper Colophon: New York, NY.

Hart G. 2008. How to hold a swishing party. Available at http://gillhart.suite101/how-to-hold-a-swishing-party-a55379 [accessed on 29 August 2011].

Hegarty E. 2010. How to organize a charity clothes swap event. Available at http://www.suite101.com/content/how-to-organize-acharity-clothes-swap-event-a278548 [accessed on 29 August 2011].

Hopkins R. 2008. The transition handbook: From oil dependency to local resilience. Green Books Ltd: Devon, UK.

Huneke ME. 2005. The face of the un-consumer: An empirical examination of the practice of voluntary simplicity in the United States. Psychology and Marketing 22(7): 527-555.

Iyer R, Muncy JA. 2009. Purpose and object of anticonsumption. Journal of Business Research 62(2): 160-168.

Izberk-Bilgin E. 2010. An interdisciplinary review of resistance to consumption, some marketing interpretations, and future research suggestions. Consumption, Markets and Culture 13(3): 299-323.

Jonsson P. 2007. A tale of a car sharing organization (CSO) monster. In Brembeck H, Ekstrom KM, Morck M (eds). Little Monsters: (de) coupling assemblages of consumption. Transaction Publishers: New Brunswick; 149-164.

Kotler P, Levy SJ. 1969. Broadening the concept of Marketing. Journal of Marketing 33(January): 10-15.

Lee D, Newby H. 1983. The Problem of Sociology: an introduction to the discipline. Unwin Hyman: London.

Lee MSW, Fernandez KV, Hyman MR. 2009 Anti-consumption: an overview and research agenda. Journal of Business Research 62(2): 145-147.

Lincoln YS, Guba EG. 1985. Naturalistic Inquiry. Sage: Beverly Hills, CA.

Mathews D. 1996. Why we need to change our concept of community leadership. Community Education Journal 23(1): 9-18.

McGregor S. 1999. Towards a rationale for integrating consumer and citizenship education. Journal of Consumer Studies and Home Economics 23(4): 207-211.

Nelson MR, Rademacher MA. 2009. From trash to treasure: Freecycle.org as a case of generalized reciprocity. Advances in Consumer Research 36: 905-906.

Nelson MR, Rademacher MA, Paek HJ. 2007. Downshifting consumer - upshifting citizen? An examination of a local freecycle community. The Annals of the American Academy of Political and Social Science 611(1): 141-156.

North P. 2010. Local money: How to make it happen in your community. Transition Books: Devon, UK.

Ozanne LK, Ballantine PW. 2010. Sharing as a form of anticonsumption? An examination of toy library users. Journal of Consumer Behaviour 9(6): 485-498.

Ozanne LK, Ozanne JL. 2011. A child's right to play: The social construction of civic virtues in toy libraries. Journal of Public Policy \& Marketing 30(2): 264-278.
Pavia T. 1993. Dispossession and perceptions of self in late stage HIV infection. Advances in Consumer Research 20: 425-428.

Penaloza L, Price LL. 1993. Consumer resistance: a conceptual overview. Advances in Consumer Research 20(1): 123-128.

Pescovitz D. 2011. The Unconsumption project. October 21. Available at http://boingboing.net/2011/10/21/the-unconsumptionproject.html [accessed on 6 January 2011].

Price JA. 1975. Sharing: The integration of intimate economies. Anthropologica 17(1): 3-27.

Price LL, Arnould EJ, Curasi CF. 2000. Older consumer's disposition of special possessions. Journal of Consumer Research 27 (September): 179-201.

Prothero A, Dobscha S, Freund J, Kilbourne WE, Luchs MG, Ozanne LK, Thogersen J. 2011. Sustainable consumption: opportunities for consumer research and public policy. Journal of Public Policy \& Marketing 30(1): 31-38.

Putnam RD. 1993. Making Democracy Work. Civic traditions in modern Italy. Princeton University Press: Princeton, NJ.

Putnam RD. 2000. Bowling Alone. The collapse and revival of American community. Simon and Schuster: New York, NY.

Sandikci ö, Ekici A. 2009. Political motivated brand rejection. Journal of Business Research 62(2): 208-217.

Schor JB. 2001. Voluntary downshifting in the 1990s. In Stanford J, Taylor L, Houston E (eds). Power, Employment, and Accumulation: Social Structures in Economic Theory and Practice. M.E. Sharpe: Armonk, NY; 66-77.

Schor JB. 2011. A Plenitude Economy. Available at www.newdream. org [accessed on 29 August 2011].

Schwartz SH. 1994. Are there universal aspects in the structure and content of human values? Journal of Social Issues 50(4): 19-45.

Selznick P. 1992. The Moral Commonwealth: Social Theory and the Promise of Community. University of California Press: Berkeley.

Shaw D, Moraes C. 2009. Voluntary simplicity: an exploration of market interactions. International Journal of Consumer Studies 33(2): 215-223.

Sherry JF. 1990. A sociocultural analysis of a Midwestern flea market. Journal of Consumer Research 17(1): 13-30.

Sheth JN, Uslay C. 2007. Implications of the revised definition of Marketing: From exchange to value creation. American Marketing Association 26(2): 302-307.

Sheth JN, Sethia NK, Srinivas S. 2011. Mindful consumption: A customer-centric approach to sustainability. Journal of the Academy of Marketing Science 39: 21-39.

Simpich B. 2004. Really Really Free Market Report. San Francisco Bay Area Indymedia. Available at http://www.indybay.org/ newsitems/2004/06/07/16839171.php [accessed on 29 August 2011].

Spradley J. 1979. The ethnographic interview. Holt, Rinehart, and Winston: New York.

The Really Really Free Market. Available at www.reallyreallyfree. org/index.php?l=Worldwide_RRFMs [accessed on 9 September 2011]. Unconsumption.org. [accessed on July 15, 2011].

Walker R. 2007. Unconsumption. The New York Times. January 7. Available at http://www.nytimes.com/2007/01/07/magazine/ 07wwln_consumed.t.html [accessed on 15 July 2011].

Walsh B. 2011. Today's smart choice: Don't own. Share. March 17, 2011. Available at www.time.com/time/specials/packages/ article/0,28804,2059521_2059717_2059710,00.html [accessed on 29 August 2011].

Walzer M. 1997. On Tolerance. Yale University Press: New Haven.

Wood GS, Judikis JC. 2002. Conversations on Community Theory. Purdue University Press: West Lafayette, Indiana.

Zavestoski S. 2002. Guest editorial: Anticonsumption attitudes. Psychology and Marketing 19(2): 121-126. 